\title{
A Polymerase - Tautomeric Model for Targeted Frameshift Mutations: Deletions Formation during Error-prone or SOS Replication of Double-stranded DNA Containing cis-syn Cyclobutane Thymine Dimers
}

\author{
Helen A. Grebneva \\ Dept. of dynamical properties of complex systems, Galkin Institute for Physics \& Engineering NAN Ukraine, Donetsk, Ukraine
}

\section{Email address:}

grebneva@gmail.com

\section{To cite this article:}

Helen A. Grebneva. A Polymerase - Tautomeric Model for Targeted Frameshift Mutations: Deletions Formation during Error-prone or SOS Replication of Double-stranded DNA Containing cis-syn Cyclobutane Thymine Dimers. Journal of Photonic Materials and Technology.

Vol. 1, No. 2, 2015, pp. 19-26. doi: 10.11648/j.jmpt.20150102.11

\begin{abstract}
Now it is still unclear how frameshift mutations arise at cyclobutane pyrimidine dimers. The author develops polymerase - tautomeric model of ultraviolet mutagenesis. The model is described that is based on the formation of rare tautomeric bases in cis-syn cyclobutane thymine dimers. A mechanism was proposed for targeted deletions caused by cis-syn cyclobutane thymine dimers. Targeted deletions are frameshift mutations when one or several nucleotides are dropped out in a DNA site opposite to a lesion capable of stopping DNA synthesis. Ultraviolet irradiation may result in changes of tautomer states of DNA bases. Thymine molecule may form 5 rare tautomer forms. They are stable if these bases are part of cyclobutane dimers. Structural analysis indicates that opposite one type of cis-syn cyclobutane thymine dimers containing a single tautomeric base $\left(\mathrm{TT}_{2}{ }^{*}\right.$, with the '*' indicating a rare tautomeric base and the subscript referring to the particular conformation) it is impossible to insert any canonical DNA bases with the template bases with hydrogen bonds formation. Therefore it is proposed that under synthesis DNA containing cis-syn cyclobutane thymine dimers $\mathrm{TT}_{2}{ }^{*}$ specialize or modified DNA polymerases will leave one nucleotide gaps opposite these cis-syn cyclobutane thymine dimers. Daughter DNA strand opposite cis-syn cyclobutane thymine dimers $\mathrm{TT}_{2}{ }^{*}$ may fall out. If in opposite DNA strand the loop is formed, daughter strand becomes shorter. Some DNA nucleotides are lost. Targeted deletion is formed. According to the polymerase-tautomeric model of ultraviolet mutagenesis cis-syn cyclobutane thymine dimers wherein a thymine is in the canonical tautomeric forms do not result in mutations. Cis-syn cyclobutane thymine dimers wherein a thymine is in the rare tautomeric forms $\mathrm{T}_{1}{ }^{*}, \mathrm{~T}_{4}{ }^{*}$, or $\mathrm{T}_{5}{ }^{*}$ were shown to cause only targeted base substitution mutations. Cis-syn cyclobutane thymine dimers wherein a thymine is in the rare tautomeric form $\mathrm{T}_{2} *$ may result in targeted frameshift mutations (targeted insertions and targeted deletions).
\end{abstract}

Keywords: UV-mutagenesis, Rare Tautomeric Forms, Targeted Frameshift Mutations, Targeted Deletion, cis-syn Thymine Cyclobutane Dimers, Error-prone Replication, SOS-replication

\section{Introduction}

UV radiation produces photoproducts in DNA. As indicated above, both cyclobutane pyrimidine dimers and (64) adducts are formed [1-6]. The most common lesions are cis-syn cyclobutane pyrimidine dimers [4], in which the bases preserve their original orientation relative to the sugarphosphate backbone [7]. Cyclobutane pyrimidine dimers and (6-4) adducts cause substutution mutations [8-19], frameshifts [11, 20,21], and complex mutations [22]. Only a few photodimers result in mutations, while more than $90 \%$ of these lesions do not [9]. Frameshift mutations are the structural DNA changes wherein one DNA strand becomes shorter or longer than the other as a result of a deletion or insertion of a number of nucleotides that is not divisible by three [23]. The point mutation rate of phage $\Phi$ X174 was determined [24]. One nucleotide deletions appear most often [25]. Frameshift mutations may be targeted and untargeted types [26]. Mononucleotide runs are hot spots for frameshift mutations in mismatch repair (MMR)-deficient cells. Frequencies of frameshift mutations increase as a function of the number of reiterated base pairs at DNA sites [27]. Both the length of a mononucleotide microsatellite and its sequence context influence mutation rate in defective DNA in 
mismatch repair (MMR)-deficient cells [28]. Ultraviolet radiation $\mathrm{C}$ (UVC) or reactive oxygen species-induced $\mathrm{CC}$ to TT tandem mutations is markedly enhanced in MMRdeficient cells. CC to TT tandem mutations in MMRdeficient cells form more readily in a homocytosine run than in a sequence limited to two cytosines [29]. The deletion frequency increases with repeat length, decreases with the distance between repeats [30]. The Y-family DNA polymerase Dpo4 make single-base deletion errors at high frequencies in repetitive sequences, especially those that contain two or more identical pyrimidines with a $5^{\prime}$ flanking guanosine [31].

The postreplicative mismatch repair (MMR) system is important for removing mutational intermediates that are generated during DNA replication, especially those that arise as a result of DNA polymerase slippage in simple repeats [32]. Both replication fidelity and MMR are affected by the microsatellite's nucleotide composition [33]. PCNA and RPA suppress large deletion errors by preventing the primer terminus at a repeat from fraying and/or from relocating and annealing to a downstream repeat [34]. DNA polymerase IV uses a template slippage mechanism to create single base deletions on homopolymeric runs [35]. DNA polymerase IV, which creates single-base deletions, prefers to extend slipped DNA substrates with the skipped base at the -4 position [36]. Overexpression of enzymes of the base excision repair pathway is known to increase the frequency of frameshift mutations [37]. Human polymerase kappa uses a classical Streisinger template-slippage mechanism to generate -1 deletions in repetitive sequences, as do the bacterial and archaeal homologues $[38,39]$. Frameshift-inducing mutagens can selectively induce mutations in mismatch repair-deficient cells versus mismatch repair-proficient cells. Environmental exposures may, therefore, favor development of cancers with microsatellite instability in tissues like the gut [40]. Cancerassociated mutations in cancer genes constitute a diverse set of mutations associated with the disease.

The Streisinger model [41] is now the best-grounded model of frameshift mutations [42-44] suggesting gaps and DNA strand slippage during synthesis as the causes of mutations. It is shown that deletions formation due to the appearance of template bases looped-out as a bulge [44]. The second model $[45,46]$ states that certain $(-1)$-frameshifts are initiated by a nucleotide misincorporation. The model [46] has been confirmed [38, 48, 49]. Functional studies and information on the structures of DNA polymerases allow refinement of Streisinger's original hypothesis and offer possible explanations for why misalignment error rates during DNA synthesis can vary by 10,000 -fold, depending on the DNA polymerase and the nucleotide composition, symmetry, and location of the synthesis error [47]. Two distinct mechanisms contribute to slipped misalignments: simple replication misalignment events are sensitive to DNA polymerase III exonuclease, whereas SCE-associated events are sensitive to exonuclease I [43]. It is proposed two mechanisms for palindrome-stimulated spontaneous deletion [50]. It is presented evidence for three mechanisms of RecA- independent sequence rearrangements: simple replication slippage, sister-chromosome exchange-associated slippage, and single-strand annealing [50]. However, the models [27, $41,45,46]$ fails to explain how cis-syn cyclobutane pyrimidine dimers result in frameshift mutations and why these lesions cause nucleotide substitutions in some cases and frameshifts in other ones.

I have attempted to construct a polymerase-tautomeric model for UV-induced mutagenesis [52-73], based on idea by Watson and Crick [74] that changes in tautomeric state are possible for DNA bases. The results of studies on the structure of the active centers polymerases show that the bases in rare tautomeric forms may exist in the active sites of polymerases [75-80]. A mechanism for changes in the tautomeric state of base pairs has been proposed $[52,54,55$, $57,61,63-65]$. It was assumed that the tautomeric state of the constituent bases may change during the formation of cyclobutane pyrimidine dimers $[57,61,63,65]$. A mechanism for changes in the tautomeric state of base pairs has been proposed for the case when DNA is UV-irradiated and cyclobutane pyrimidine dimers are formed $[61,63]$. Five new rare tautomeric conformations of A:T $[61,63]$ and G:T $[56,62]$ base pairs are proposed that are capable of influencing the character of base pairing. The rare tautomeric forms of bases are stable at cis-syn cyclobutane pyrimidine dimers formation and in DNA synthesis [63, 65]. The part of cis-syn cyclobutane pyrimidine dimers with bases in certain rare tautomeric forms may result in targeted substitution mutations $[58,64,66]$. Three mechanisms for untargeted substitution mutations formation also have been developed $[60,62,67$, 69]. A model was developed for the formation of hot and cold spots of UV-induced mutagenesis [68]. A mechanisms was proposed for targeted insertions [70, 71], targeted complex insertions [73] and targeted deletions (provisional article [72]) caused by cis-syn cyclobutane thymine dimers. Cis-syn cyclobutane thymine dimers with bases in certain rare tautomeric forms may result in targeted frameshift mutations. A structural analysis showed that none of the canonical nucleotides can be incorporated opposite to these cis-syn cyclobutane thymine dimers [70-72]. In this paper a mechanism was proposed for targeted deletions caused by cis-syn cyclobutane thymine dimers.

\section{Error-prone or SOS DNA Synthesis on a Template Containing cis-syn Thymine Dimers}

If not removed by the repair mechanisms, cyclobutane pyrimidine dimers may allow targeted mutations to arise during error-prone or SOS synthesis. Incorrect bases can be inserted when DNA containing cyclobutane pyrimidine dimers acts as the template for error-prone or SOSreplication, repair, or transcription [81-84]. The mutations that result from these incorrect bases are often targeted; that is, they occur at the same position as the cyclobutane pyrimidine dimers $[9,10,13]$. Mutations arise when 
modified [85] or specialized [86-97] DNA polymerases are involved in DNA synthesis.

Modified or specialized DNA polymerases incorporate canonical bases capable of forming hydrogen bonds with dimerized bases in template DNA [64]. Error-prone DNA synthesis proceeds the same way as error-free synthesis. When a canonical nucleotide cannot be added opposite to a cyclobutane pyrimidine dimer so that the opposite bases are hydrogen bonded, specialized or modified DNA polymerases leave a one-nucleotide gap. For instance, this is the case when an abasic site occurs in the template, leading to onenucleotide deletion [25].

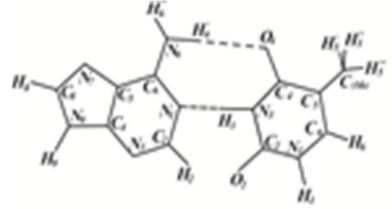

A

a)

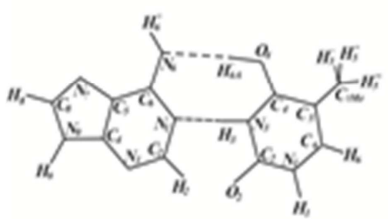

$\vec{A}$

c)

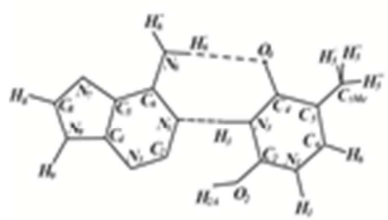

$\Delta \cdot$

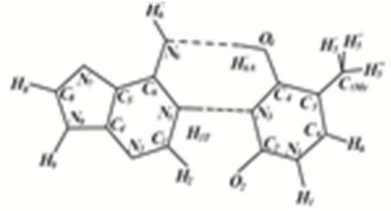

$\Delta ;$

b)

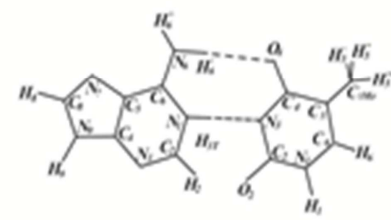

$A ;$

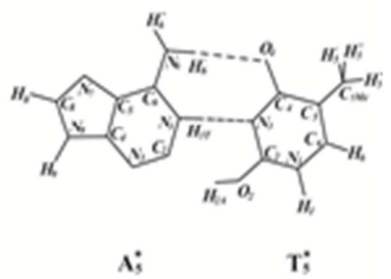

ก
Fig. 1. Rare tautomeric states of thymine and adenine. (a) Watson-Crick pair $A-T$ and $(b-h)$ rare tautomeric states possible for thymine and adenine upon UV irradiation of DNA.

Frameshift mutations most commonly arise in DNA sites with a homogenous nucleotide composition, such as monotonous runs of G-C or A-T pairs. Five rare tautomeric forms are possible for thymine (Fig. 1) [63]. The forms are stable when the respective bases are involved in cyclobutane thymine dimers $[63,64]$. This is because the DNA strand bends once pyrimidine dimers arise, and the hydrogen bonds between the bases are broken between the bases that neighbor the cyclobutane pyrimidine dimers [4, 98-101]. Consider a DNA site with a homogenous nucleotide composition wherein one strand contains cis-syn cyclobutane dimers $\mathrm{TT}_{2}$ * (Fig. 1). One base of the dimer is a canonical thymine (T), and the other is the rare tautomeric form $\mathrm{T}_{2} *$ (Fig. 2a). The question is how deletions of one or more nucleotides can form in this case. Let us the site is replicated by error-free DNA polymerases. In result a post replicate gap may appear opposite cyclobutane dimers (Fig. 2b). Let us the post replicate gap is replicated by specialized or modified DNA polymerases in result error-prone or SOS synthesis.

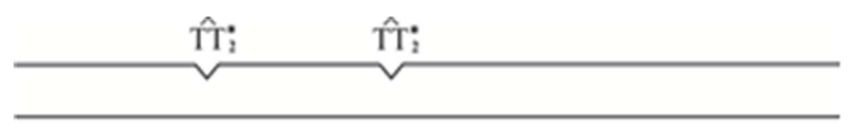

a)

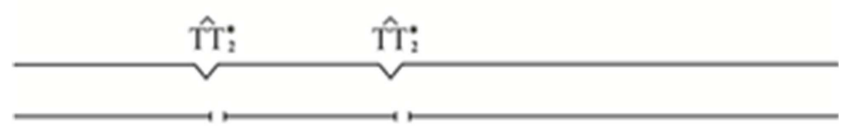

b)

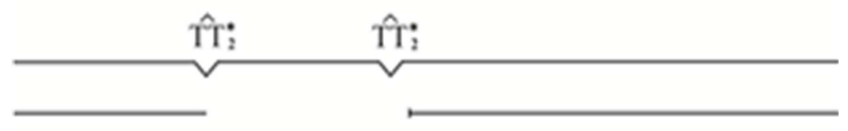

c)

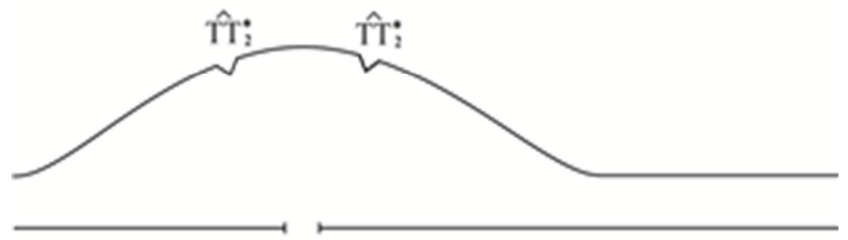

d)

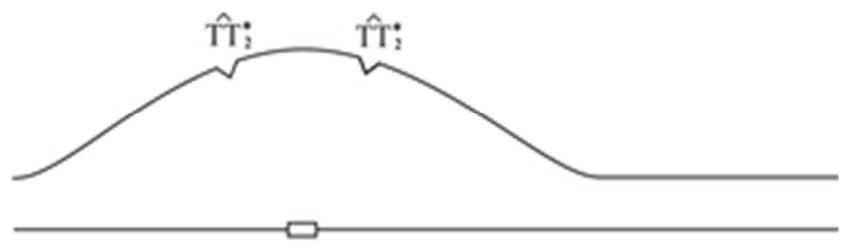

e)

Fig. 2. Generation of a targeted deletion of several nucleotides. a) A DNA site contains the cis-syn cyclobutane thymine dimers $T T_{2}^{*}$; b) a post replicative gap arises opposite to cis-syn cyclobutane dimers $T_{2}{ }^{*}$; c) post replicative gap is filled using modified or specialized DNA polymerases. One-nucleotide gaps arise opposite to the cis-syn cyclobutane thymine dimers $T_{2}{ }^{*}$; d) site of the DNA strand is lost; e) a loop forms; f) the gap is filled. An insertion of several nucleotides formed, but smaller than the fallen DNA site. A targeted deletion of several nucleotides is formed.

A structural analysis is performed for the incorporation of DNA nucleotides opposite to $\mathrm{T}_{2} *$ (Fig. 3b) to identify the canonical nucleotides that can be inserted opposite to $\mathrm{T}_{2} *$ to allow hydrogen bonding of the two bases. Canonical thymine cannot be inserted opposite to $\mathrm{T}_{2}{ }^{*}$ by DNA polymerase because of repulsion between the hydrogen $\mathrm{H}_{3}$ of the canonical thymine and $\mathrm{H}_{3}$ of $\mathrm{T}_{2} *$ (Fig. 3c). Adenine cannot be inserted because of repulsion between $\mathrm{H}^{\prime}{ }_{6}$ of adenine and $\mathrm{H}_{6 A}^{\prime}$ of $\mathrm{T}_{2}{ }^{*}$ (Fig. 3d). Cytosine incorporation is prevented by repulsion between $\mathrm{H}_{4}{ }^{\prime}$ of cytosine and $\mathrm{H}_{6 A}^{\prime}$ of $\mathrm{T}_{2}{ }^{*}$ (Fig. 3e), and guanine incorporation is prevented by repulsion between $\mathrm{H}^{\prime}{ }_{1}$ of guanine and $\mathrm{H}_{3}$ of $\mathrm{T}_{2}{ }^{*}$ (Fig. 3f). That is, none of the canonical bases can be incorporated opposite to $\mathrm{T}_{2} *$. 


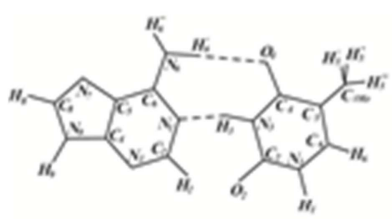

$\mathbf{A}$

a)
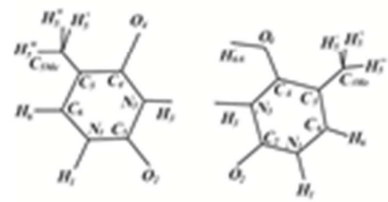

$\mathbf{T}_{i}^{*}$

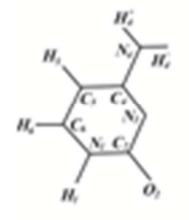

C

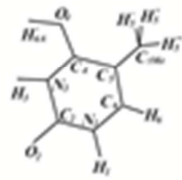

$\mathbf{T}_{2}$

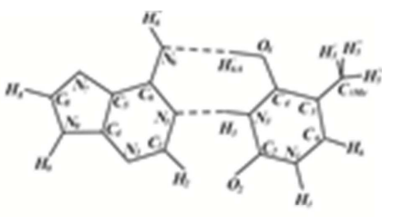

$A_{;}$

b)

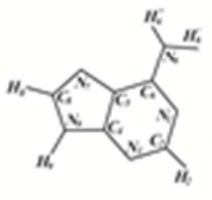

$\mathbf{A}$

d)

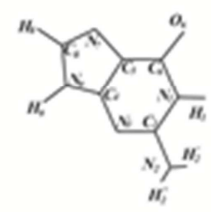

G

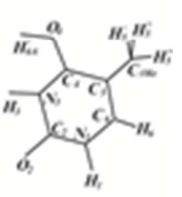

$\mathbf{T}_{i}^{*}$

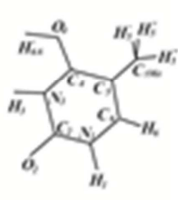

$\mathbf{T}^{*}$
Fig. 3. Possible base pairs formed between thymine in rare tautomeric conformations $T_{2}{ }^{*}$ and bases in canonical tautomeric conformations. (a) A:T canonical pair; (b) $A_{2}{ }^{*}: T_{2}^{*}$ pair, wherein the bases are in the rare tautomeric state; (c) $T_{2} *$ and thymine; (d) $T_{2} *$ and adenine; (e) $T_{2} *$ and cytosine; (f) $T_{2} *$ and guanine.

A one-nucleotide gap arises opposite to a cis-syn cyclobutane dimer $\mathrm{TT}_{2}{ }^{*}$ (Fig. 2b) as a result of translesion synthesis driven by modified E. coli DNA polymerase III or mammalian DNA polymerase $\delta$ or $\varepsilon$ or specialized (mammalian Pol $\eta$ or Pol $\zeta$ or E. coli DNA polymerase IV or V) DNA polymerases. As was demonstrated experimentally, such a gap arises during DNA synthesis when the template contains an abasic site, leading to a one-nucleotide deletion [25]. The site in nascent DNA strand may be lost (Fig. 2c) because a bend forms in the site containing cyclobutane pyrimidine dimers and the hydrogen bonds between the bases are broken [4, 98-101]. A DNA site containing the cis-syn cyclobutane dimers $\mathrm{TT}_{2}{ }^{*}$, may form a loop as shown in Figure 2e. The resulting smaller gap is usually filled in by constitutive DNA polymerases (Fig. 2f), leading to the precipitation of several bases (deletion formation).

One nucleotide deletions appear most often. In this case, one nucleotide falls. This deletion may cause a one cis-syn cyclobutane dimer $\mathrm{TT}_{2} *$ (Fig. 4). A one-nucleotide gap arises opposite to a cis-syn cyclobutane dimer $\mathrm{TT}_{2} *$ (Fig. 4b) as a result of translesion synthesis. DNA strand containing cis-syn cyclobutane dimer $\mathrm{TT}_{2} *$ may form a small loop (Fig. 4c). In this case, the DNA site containing the gap is shifted by one nucleotide and DNA strand is connected to a new place (Fig. $4 \mathrm{c})$. This is possible because the frameshift mutations are formed on homogeneous site of the DNA, in this case, consisting only of thymine molecules.

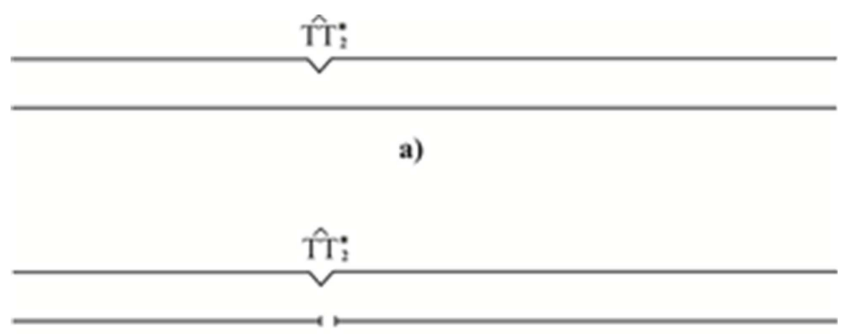

b)

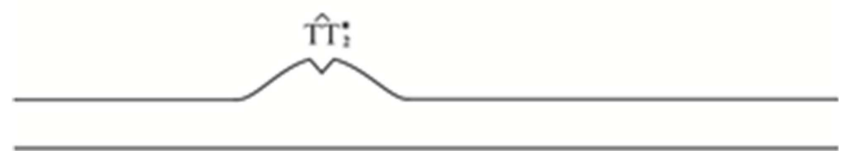

c)

Fig. 4. Generation of a one-nucleotide targeted deletion. (a) A DNA site contains the cis-syn cyclobutane thymine dimer $T T_{2}^{*}$; (b) one-nucleotide gaps arise opposite to the cis-syn cyclobutane thymine dimer $\mathrm{TT}_{2}{ }^{*}$; (c) DNA strand containing cis-syn cyclobutane dimer $T T_{2}^{*}$ forms a small loop. The DNA site containing the gap is shifted by one nucleotide. A one-nucleotide targeted deletion is formed.

Thus, cis-syn cyclobutane thymine dimers wherein one or both of the bases occur in the rare tautomeric states that prevent their hydrogen bonding with canonical DNA bases are a possible source of frameshift mutations and, in particular, deletions. The above mechanisms of deletions formation agree with the models $[27,41,45,46]$.

\section{Conclusion}

To further develop the polymerase-tautomeric model of UV-induced mutagenesis, a mechanism was proposed for targeted deletions (frameshift mutations) caused by cis-syn cyclobutane thymine dimers. A structural analysis showed that none of the canonical nucleotides can be incorporated opposite to a cis-syn cyclobutane thymine dimer $\mathrm{TT}_{2}{ }^{*}$ with formation of hydrogen bonds between the $\mathrm{T}_{2}{ }^{*}$ bases of the template DNA and the inserted canonical bases. The analysis is based on the fact that the canonical bases capable of hydrogen bonding with template DNA bases are incorporated opposite to cyclobutane dimers by specialized or modified DNA polymerases during DNA synthesis [63]. Doublestranded DNA synthesis was considered for the case where one of the strands contains cis-syn cyclobutane thymine dimers wherein one or both of the bases occur in the rare tautomeric state $\mathrm{T}_{2}{ }^{*}$. When modified or specialized DNA polymerases drive the synthesis, a one-nucleotide gap can arise opposite to a cis-syn cyclobutane thymine dimer containing $\mathrm{T}_{2}{ }^{*}$. The DNA strand is bent and H-bonds between the bases are broken [4, 98-101]. Therefore, the DNA site opposite of the cis-syn cyclobutane dimers $\mathrm{TT}_{2} *$ be lost. The DNA site containing the cis-syn cyclobutane dimers $\mathrm{TT}_{2}{ }^{*}$, may form a loop. A daughter strand becomes shorter. As a result, several DNA nucleotides fall and a deletion is formed. One cis-syn cyclobutane dimer $\mathrm{TT}_{2}{ }^{*}$ may result in onenucleotide deletion. A one-nucleotide gap can arise opposite to a cis-syn cyclobutane thymine dimer $\mathrm{TT}_{2}{ }^{*}$. The DNA site 
containing one cis-syn cyclobutane dimer $\mathrm{TT}_{2}{ }^{*}$, may form a small loop. A daughter strand shift on one nucleotide and one-nucleotide deletion is formed.

According to the polymerase-tautomeric model of ultraviolet mutagenesis cis-syn cyclobutane thymine dimers wherein a thymine is in the canonical tautomeric forms do not result in mutations [63]. Cis-syn cyclobutane thymine dimers wherein a thymine is in the rare tautomeric form $\mathrm{T}_{2}{ }^{*}$ may result in targeted frameshift mutations (targeted insertions and targeted deletions) [69-71]. Cis-syn cyclobutane thymine dimers wherein a thymine is in the rare tautomeric forms $\mathrm{T}_{1}{ }^{*}, \mathrm{~T}_{4}{ }^{*}$, or $\mathrm{T}_{5}{ }^{*}$ were shown to cause only targeted base substitution mutations [63]. I propose the mechanisms of targeted insertions formation during errorprone or SOS synthesis of DNA containing cis-syn cyclobutane thymine [69] and cytosine [70] dimers. Therefore, the cis-syn cyclobutane thymine dimers that contain the rare tautomeric form $\mathrm{T}_{2}{ }^{*}$ were demonstrated to cause targeted frameshift mutations. Thus, different targeted mutations, including both nucleotide substitutions and frameshifts, can be explained in the context of the polymerase-tautomeric model of UV-induced mutagenesis. In addition, the model is able to explain nature and mechanisms formation of targeted complex ultraviolet mutations [72], mechanisms of hot and cold spots formation [67] and mechanisms of untargeted base substitution mutations formation [68].

\section{References}

[1] C.W. Lawrence, R.B. Christensen and J.R. Christensen, "Identity of the photoproduct that cause lacI mutations in UVirradiated Escherichia coli”, J. Bacter., vol. 161, pp. 767-768, 1985.

[2] D. Chandrasekhar and B.V. Houten, "In vivo formation and repair of cyclobutane pyrimidine dimers and 6-4 photoproducts measured at the gene and nucleotide level in Escherichia coli", Mutat. Res., vol. 450, pp. 19-40, 2000.

[3] J. Yao, K. Dixon and M.P. Carty, "A single (6-4) photoproduct inhibits plasmid DNA replication in xeroderma pigmentosum variant cell extracts", Environ. Mol. Mutagen., vol. 38, pp. 19-29, 2001.

[4] H.M. Bdour, J.L. Kao and J.S. Taylor, "Synthesis and characterization of a [3-15N]-labeled cis-syn thymine dimercontaining DNA duplex", J. Org. Chem., vol. 71, pp. 16401646, 2006.

[5] A. Besaratinia, J.I. Yoon, C. Schroeder, S.E. Bradforth, M. Cockburn and G.P. Pfeifer. "Wavelength dependence of ultraviolet radiation-induced DNA damage as determined by laser irradiation suggests that cyclobutane pyrimidine dimers are the principal DNA lesions produced by terrestrial sunlight", FASEB. J., vol. 25, pp. 3079-3091, 2011.

[6] A. Banyasz, I. Vayá, P. Changenet-Barret, T. Gustavsson, T. Douki and D. Markovitsi. "Base pairing enhances fluorescence and favors cyclobutane dimer formation induced upon absorption of UVA radiation by DNA", J. Am. Chem. Soc., vol. 133, pp. 5163-5165, 2011.
[7] W. Saenger, Principles of Nucleic Acid Structure. New York: Springer-Verlag New York Inc. 1984.

[8] J.E. LeClerc and N.L. Istock. "Specificity of UV-mutagenesis in the lac-promoter of M13 hybrid phage DNA", Nature, vol. 297, pp. 596-598, 1982.

[9] C.W. Lawrence, S.K. Banerjee, A. Borden and J.E. LeClerc, "T-T cyclobutane dimers are misinstructive, rather than noninstructive, mutagenic lesions", Mol. Gen. Genet., vol. 222, pp. 166-169, 1990.

[10] J.E. LeClerc, A. Borden and C.W. Lawrence, "The thyminethymine pyrimidine-pyrimidine (6-4) ultraviolet light photoproduct is highly mutagenic and specifically induces $3^{\prime}$ thymine-to-cytosine transitions in Escherichia coli", Proc. Natl. Acad. Sci. USA, vol. 88, pp.9685-9689, 1991.

[11] C.I. Wang and J.S. Taylor, "In vitro evidence that UV-induced frameshift and substitution mutations at $\mathrm{T}$ tracts are the result of misalignment-mediated replication past a specific thymine dimer”, Biochemistry, vol. 31, pp.3671-3681, 1992.

[12] C.W. Lawrence, P.E.M. Gibbs, A. Borden, M.J. Horsfall and B.Y. Kilbey, "Mutagenesis induced by single UV photoproducts in $E$. coli and yeast", Mutat. Res., vol. 299, pp. 157-163, 1993.

[13] C.W. Lawrence, "Accuracy of replication past the T-C (6-4) adduct”, J. Mol. Biol., vol. 235, pp. 465-471, 1994.

[14] P.E.M. Gibbs, A. Borden and C.W. Lawrence, "The T-T pyrimidine (6-4) pyrimidone UV photoproduct is much less mutagenic in yeast than in Escherichia coli", Nucleic Acids Res., vol. 23, pp. 1919-1922, 1995.

[15] J.E. LeClerc, W.L. Payne and T.A. Cebula, "High mutation frequencies among Escherichia coli and Salmonella pathogens", Science, vol. 274, pp. 1208-1211, 1996.

[16] D.J. Moshinsky and G.N. Wogan, "UV-induced mutagenesis of human p53: analysis using a double-selection method in yeast", Environ. Mol. Mutagen., vol. 35, pp. 31-38, 2000.

[17] X. Veaute, G. Mari-Giglia, C.W. Lawrence and A. Sarasin, "UV lesions located on the leading strand inhibit DNA replication but do not inhibit SV40 T-antigen helicase activity", Mutat. Res., vol. 459, pp. 19-28, 2000.

[18] Y.-H. You, D.H. Lee, J.-H. Yoon, S. Nakajima, A. Yasui and G.P. Pfeifer, "Cyclobutane pyrimidine dimers are responsible for the vast majority of mutations induced by UVB irradiation in mammalian cells", J. Biol. Chem., vol. 276, pp. 4468844694, 2001.

[19] J.E. Trosko, "From bacteria to humans: lessons learned from a reductionist's view of ultraviolet light-induced DNA lesions", Environ. Mol. Mutagen., vol. 38, pp. 118-121, 2001.

[20] A.L. Abdulovic and S. Jinks-Robertson, "The in vivo characterization of translesion synthesis across UV-induced lesions in Saccharomyces cerevisiae: insights into Pol $\zeta$ - and Pol $\eta$-dependent frameshift mutagenesis", Genetics, vol. 172, pp. 1487-1498, 2006.

[21] P. Iengar, "An analysis of substitution, deletion and insertion mutations in cancer genes", Nucleic. Acids. Res., vol. 40, pp. 6401-6413, 2012.

[22] J.G. Levine, R.M. Schaaper and D.M. DeMarini, "Complex frameshift mutations mediated by plasmid pKM101: mutational mechanisms deduced from 4-aminobiphenylinduced mutation spectra in Salmonella", Genetics, vol. 136, pp. 731-746, 1994. 
[23] S. Shibutani, M. Takeshita and A.P. Grollman, "Insertion of specific bases during DNA synthesis past the oxidationdamaged base 8-oxoG", Nature, vol. 349, pp. 431-434, 1991.

[24] J.M. Cuevas, S. Duffy and R. Sanjuán, "Point mutation rate of bacteriophage $\{$ Phi\} X174", Genetics, vol. 183, pp. 747-749, 2009.

[25] S. Kobayashi, M.R. Valentine, P. Pham, M. O'Donnell and M.F. Goodman, "Fidelity of Escherichia coli DNA polymerase IV. Preferential generation of small deletion mutations by dNTP-stabilized misalignment", J. Biol. Chem., vol. 277, pp. 34198-34207, 2002.

[26] S.R. Kim, K. Matsui, P. Yamada, P. Gruz and T. Nohm, "Roles of chromosomal and episomal $\operatorname{din} B$ genes encoding Pol IV in targeted and untargeted mutagenesis in Escherichia coli", Mol. Genet. Genomics, vol. 266, pp. 207-215, 2001.

[27] G. Streisinger and J. Owen, "Mechanisms of spontaneous and induced frameshift mutation in bacteriophage T4", Genetics, vol. 109, pp. 633-659, 1985.

[28] H. Chung, C.G. Lopez, J. Holmstrom, D.J. Young, J.F. Lai, D. Ream-Robinson and J.M. Carethers, "Both microsatellite length and sequence context determine frameshift mutation rates in defective DNA mismatch repair", Hum. Mol. Genet., vol. 19 , pp. 2638-2647, 2010.

[29] A.M. Skinner, C. Dan and M.S. Turker, "The frequency of CC to TT tandem mutations in mismatch repair-deficient cells is increased in a cytosine run", Mutagenesis, vol. 23, pp. 87-91, 2008.

[30] J.M. Gore, F.A. Ran and L.N. Ornston, "Deletion mutations caused by DNA strand slippage in Acinetobacter baylyi", Appl. Environ. Microbiol., vol. 72, pp. 5239-5245, 2006.

[31] Y. Wu, R.C. Wilson and J.D. Pata, "The Y-family DNA polymerase Dpo4 uses a template slippage mechanism to create single-base deletions", J. Bacteriol., vol. 193, pp. 26302636, 2011

[32] H. Gragg, B.D. Harfe and S. Jinks-Robertson, "Base composition of mononucleotide runs affects DNA polymerase slippage and removal of frameshift intermediates by mismatch repair in Saccharomyces cerevisiae", Mol. Cell Biol., vol. 22, pp. 8756-8762, 2002.

[33] Campregher, T. Scharl, M. Nemeth, C. Honeder, T. Jascur, R.B. Boland and C. Gasche, "The nucleotide composition of microsatellites impacts both replication fidelity and mismatch repair in human colorectal cells", Hum. Mol. Genet., vol. 19, pp. 2648-2657, 2010.

[34] J.M. Fortune, C.M. Stith, G.E. Kissling, P.M.J. Burgers and T. Kunkel, "RPA and PCNA suppress formation of large deletion errors by yeast DNA polymerase \{delta\}", Nucleic Acids Res., vol. 34, pp. 4335-4341, 2006.

[35] J.J. Foti, A.M. DeLucia, C.M. Joyce and G.C. Walker, "UmuD2 inhibits a non-covalent step during DinB-mediated template slippage on homopolymeric nucleotide runs", J. Biol. Chem., vol. 285, pp. 23086-23095, 2010.

[36] J.J. Foti and G.C. Walker, "Efficient extension of slipped DNA intermediates by DinB is required to escape primer template realignment by DnaQ", J. Bacteriol., vol. 193, pp. 2637-2641, 2011.

[37] D.M. Lyons and P.J. O'Brien, "Human base excision repair creates a bias toward -1 frameshift mutations", J. Biol. Chem., vol. 285, pp. 25203-25212, 2010.

[38] H. Zhang, J.W. Beckman and F.P. Guengerich, "Frameshift deletion by Sulfolobus solfataricus P2 DNA polymerase Dpo4 $\mathrm{T} 239 \mathrm{~W}$ is selective for purines and involves normal conformational change followed by slow phosphodiester bond formation", J. Biol. Chem., vol. 284, pp. 35144-35153, 2009.

[39] P. Mukherjee, I. Lahiri and J.D. Pata, "Human polymerase kappa uses a template-slippage deletion mechanism, but can realign the slipped strands to favour base substitution mutations over deletions", Nucleic Acids Res., vol. 41, pp. 5024-5035, 2013.

[40] W.-D. Chen, J.R. Eshleman, M.R. Aminoshariae, A.-H. Ma, N. Veloso, S.D. Markowitz, W.D. Sedwick and M.L. Veig, "Cytotoxicity and mutagenicity of frameshift-inducing agent ICR191 in mismatch repair-deficient colon cancer cells", J. Natl. Cancer. Inst., vol. 92, pp. 480-485, 2000.

[41] G. Streisinger, J. Okada, J. Emerich, J. Newrich, A. Tsugita, E. Terraghi, M. Inouye, "Frameshift mutations and the genetic code", Cold Spring Harbor Symp. Quant. Biol., vol. 31, pp. 77-84, 1966.

[42] M. Strand, T.A. Prolla, R.M. Liskay and T.D. Petes, "Destabilization of tracts of simple repetitive DNA in yeast by mutations affecting DNA mismatch repair", Nature, vol. 365, pp. 274-276, 1993.

[43] M. Bzymek, C.J. Saveson, V.V. Feschenko and S.T. Lovett, "Slipped misalignment mechanisms of deletion formation: in vivo susceptibility to nucleases", J. Bacteriol., vol. 181, pp. 477-482, 1999

[44] W.A. Baase, D. Jose, B.C. Ponedel, P.H. von Hippel and N.P. Johnson, "DNA models of trinucleotide frameshift deletions: the formation of loops and bulges at the primer-template junction”, Nucleic Acids Res., vol. 37, pp. 1682-1689, 2009.

[45] T.A. Kunkel and A. Soni, "Mutagenesis by transient misalignment”, J. Biol. Chem., vol. 263, pp. 14784-14789, 1988.

[46] K. Bebenek and T.A. Kunkel, "Mutagenesis by transient misalignment", Proc. Natl. Acad. Sci. USA, vol. 87, pp. 49464950,1990

[47] K. Bebenek and T.A. Kunkel, "Streisinger revisited: DNA synthesis errors mediated by substrate misalignments", Cold Spring Harb. Symp. Quant. Biol., vol. 65, pp. 81-92, 2000.

[48] P.T. Pham, M.W. Olson, C.S. McHenry and R.M. Schaaper, "The base substitution and frameshift fidelity of Escherichia coli DNA polymerase III holoenzyme in vitro", J. Biol. Chem., vol. 273, pp. 23575-23584, 1998.

[49] J. Bauer, G. Xing, H. Yagi, J.M. Sayer, D.M. Jerina and H. Ling, "A structural gap in Dpo4 supports mutagenic bypass of a major benzo[a]pyrene dG adduct in DNA through template misalignment", Proc. Natl. Acad. Sci. USA, vol. 104, pp. 14905-14910, 2007.

[50] M. Bzymek and S.T. Lovett, "Evidence for two mechanisms of palindrome-stimulated deletion in Escherichia coli: singlestrand annealing and replication slipped mispairing", Genetics, vol. 158, pp. 527-540, 2001.

[51] M. Bzymek, S.T. Lovett, "Instability of repetitive DNA sequences: The role of replication in multiple mechanisms", Proc. Natl. Acad. Sci. USA, vol. 98, pp. 8319-8325, 2001. 
[52] H.A. Grebneva, "Possible mechanism of formation of rare tautomeric forms of nucleotide bases on the example of UVirradiation of DNA", Ukr. Phys. J., vol. 37, pp. 1636-1639, 1992.

[53] H.A. Grebneva, "The role of hydrogen bonds in the formation of genetic mutations", Chem. Phys. (Mosk.), vol. 12, pp. $1027-1031,1993$

[54] H.A. Grebneva, "The heat deexcitation as mechanism of double proton transitions in DNA", Dopovidi NAN Ukraine, vol. 2, pp. 73-75, 1994.

[55] H.A. Grebneva, "The irradiation of DNA by ultraviolet light: potential alterations and mutations", Mol. Biol. (Mosk.), vol. 28, pp. 805-812, 1994.

[56] H.A. Grebneva, "Proton potential for broad spectrum of hydrogen bond length in water dimer", Zh. Struckt. Khim., vol 38, pp. 422-430, 1997.

[57] H.A. Grebneva, "The molecular mechanisms derivation of mutation bases alteration after a post replication SOS-repair a DNA containing thymine dimers", Biopolymers Cell (Ukr.), vol. 17, pp. 487-500, 2001.

[58] H.A. Grebneva, "Mechanisms of formation of potential mutations under cytosine dimers formation in result irradiation double-stranded DNA by ultraviolet light", Dopovidi NAN Ukraine, vol. 7, pp. 165-169, 2001.

[59] H.A. Grebneva, "Targeted mutagenesis caused by cytosine dimers and mechanism substitution mutation formation under SOS-replication after airradiation double-stranded DNA by ultraviolet light”, Dopovidi NAN Ukraine, vol. 8, pp. 183-189, 2001.

[60] H.A. Grebneva, Ivanov M.O. 2001. "The possible molecular mechanisms of untargeted type mutation under SOS replication of double-stranded DNA", Biopolymers Cell (Ukr.), vol. 17, pp. 388-395 2001.

[61] H.A. Grebneva, "The nature and possible mechanisms of potential mutations formation due to the appearance of thymine dimers after irradiating double-stranded DNA by ultra-violet light", Biopolymers Cell (Ukr.), vol. 18, pp. 205218, 2002.

[62] H.A. Grebneva, "Possible molecular mechanisms of untargeted mutagenesis upon a post-replication SOSreparation after irradiating double-stranded DNA by ultraviolet light", Biopolymers Cell (Ukr.), vol. 18, pp. 394400, 2002.

[63] H.A. Grebneva, "Nature and possible mechanisms formation of potential mutations arising at emerging of thymine dimers after irradiation of double-stranded DNA by ultraviolet light", J. Mol. Struct., vol. 645, pp. 133-143, 2003.

[64] H.A. Grebneva, "One of mechanisms of targeted substitution mutations formation at SOS-replication of double-stranded DNA containing cis-syn cyclobutane thymine dimers", Environ. Mol. Mutagen., vol. 47, pp. 733-745, 2006.

[65] H.A. Grebneva, 2008. "A polymerase-tautomeric model of UV mutagenesis: Formation of rare tautomeric forms of cytosine and guanine in double-stranded DNA", Vestn. Donetsk Univ. (Ukr.), vol. 2, pp. 306-313, 2008.

[66] H.A. Grebneva, "Targeted base-substitution mutations during the synthesis of double-stranded DNA containing cis-syn cyclobutane pyrimidine dimers", Vestn. Donetsk Univ. (Ukr.), vol. 1, pp. 323-330, 2009.

[67] H.A. Grebneva, "Mechanism of untargeted substitution mutations formation during error-prone and SOS-synthesis of double-stranded DNA containing cis-syn cyclobutane cytosine dimers in both DNA strands", Vestn. Donetsk Univ. (Ukr.), vol. 2, pp. 132-138, 2011

[68] H.A. Grebneva, "The nature and formation mechanisms of hot and cold spots for UV mutagenesis", Dopovidi NAN Ukraine, vol. 10, pp. 181-187, 2012.

[69] H.A. Grebneva, "Three sources of untargeted basesubstitution mutations upon UV irradiation of DNA molecule", Dopovidi NAN Ukraine, vol. 1, pp. 143-150, 2013.

[70] H.A. Grebneva, "Mechanisms of targeted frameshift mutations: insertions arising during error-prone or SOS synthesis of DNA containing cis-syn cyclobutane thymine dimers", Mol. Biol. (Mosk.), vol. 48, pp. 457-467, 2014.

[71] H.A. Grebneva, "Mechanisms targeted insertions formation under synthesis of DNA molecule containing cis-syn cyclobutane cytosine dimers", Dopovidi NAN Ukraine, vol. 11, pp. 156-164, 2014.

[72] H.A. Grebneva, "Mechanisms targeted deletions formation under synthesis of DNA molecule containing cis-syn cyclobutane thymine dimers", Dopovidi NAN Ukraine, vol. 4, pp. 124-132, 2015.

[73] H.A. Grebneva, "Mechanisms of targeted complex insertions formation under synthesis of DNA molecule containing cissyn cyclobutane thymine dimers", Dopovidi NAN Ukraine, vol. 5, pp. 145-154, 2015.

[74] J.D. Watson and F.H.C. Crick. "The structure of DNA", Cold Spring Harbor Symp. Quant. Biol., vol. 18, pp. 123-131, 1953.

[75] K. Bebenek, L.C. Pedersen and T. Kunkel. "Replication infidelity via a mismatch with Watson-Crick geometry", Proc. Natl. Acad. Sci. USA, vol. 108, pp. 1862-1867, 2011.

[76] W. Wang, H.W. Hellinga and L.S. Beese. "Structural evidence for the rare tautomer hypothesis of spontaneous mutagenesis", Proc. Natl. Acad. Sci. USA, vol. 108, pp. 17644-17648, 2011.

[77] C.S. Peng, C.R. Baiz and A. Tokmakoff. "Direct observation of ground-state lactam-lactim tautomerization using temperature-jump transient 2D IR spectroscopy”, Proc. Natl. Acad. Sci. USA, vol. 110, pp. 9243-9248, 2013.

[78] D. Li, B.I. Fedeles, V. Singh, C.S. Peng, K.J. Silvestre, A.K. Simi, J.H. Simpson, A. Tokmakoff and J.M. Essigmann. "Tautomerism provides a molecular explanation for the mutagenic properties of the anti-HIV nucleoside 5-aza-5,6dihydro-2'-deoxycytidine", Proc. Natl. Acad. Sci. USA, vol. 11, pp. E3252-E3259, 2014.

[79] S. Xia and W.H. Konigsberg. "Mispairs with Watson-Crick base-pair geometry observed in ternary complexes of an RB69 DNA polymerase variant”, Protein Sci., vol. 23, pp. 508-513, 2014.

[80] V. Singh, B.I. Fedeles and J.M. Essigmann. "Role of tautomerism in RNA biochemistry", RNA, vol. 21, pp. 1-13, 2015. 
[81] S.K. Banerjee, A. Borden, R.B. Christensen, J.E. LeClerc and C.W. Lawrence. "SOS-dependent replication past a single trans-syn T-T cyclobutane dimer gives a different mutation spectrum and increased error rate compared with replication past this lesion in induced cells", J. Bacteriol., vol. 172, pp. 2105-2112, 1990

[82] B.A. Kunz, A.F.L. Straffon and E.J. Vonarx. "DNA damageinduced mutation: tolerance via translesion synthesis", Mutat. Res., vol. 45, pp. 169-185, 2000.

[83] P.-M. Leong-Morgenthaler, R. Duc and S. Morgenthaler. "Comparison of the mutagenic responses of mismatch repairproficient (TK6) and mismatch repair-deficient (MT1) human lymphoblast cells to the food-borne carcinogen PhlP”, Environ. Mol. Mutagen., vol. 38, pp. 323-328, 2001.

[84] P.W. Doetsch. "Translesion synthesis by RNA polymerases: occurrence and biological implications for transcriptional mutagenesis", Mutat. Res., vol. 510, pp. 131-140, 2002.

[85] A. Furukohri, M.F. Goodman and H.A. Maki. "Dynamic polymerase exchange with Escherichia coli DNA polymerase IV replacing DNA polymerase III on the sliding clamp", J. Biol. Chem., vol. 283, pp. 11260-11269, 2008.

[86] J.R. Nelson, C.W. Lawrence and D.C. Hinkle. "Deoxycytidyl transferase activities of years REV 1 protein", Nature, vol. 382, pp. 729-731, 1996.

[87] M. Tang, X. Shen, E.G. Frank, M. O’Donnell, R. Woodgate and M.F. Goodman. "UmuD' $(2) \mathrm{C}$ is an error-prone DNA polymerase. Escherichia coli pol V", Proc. Natl. Acad. Sci. USA, vol. 96, pp. 8919-8924, 1999.

[88] M. Tang, P. Pham, X. Shen, J.-S. Taylor, M. O'Donnell, R. Woodgate and M. Goodman. "Roles of Escherichia coli DNA polymerase IV and V in lesion-targeted and untargeted SOS mutagenesis", Nature, vol. 404, pp.1014-1018, 2000.

[89] M.T. Washington, R.E. Johnson, S. Prakash and L. Prakash. "Accuracy of thymine-thymine dimer bypasses by Saccharomyces cerevisiae DNA polymerase eta", Proc. Natl. Acad. Sci. USA, vol. 97, pp. 3094-3099, 2000.

[90] R.E. Johnson, L. Haracska, S. Prakash and L. Prakash. "Role of DNA polymerase zeta in the bypass of a (6-4) TT photoproduct”, Mol. Cell. Biol., vol. 21, pp. 3558-3563, 2001.

[91] C.W. Lawrence, "Cellular roles DNA polymerase zeta and Rev1 protein”, DNA repair, vol. 1, pp. 425-435, 2002.

[92] M.T. Washington, L. Prakash and S. Prakash, "Mechanism of nucleotide incorporation opposite a thymine-thymine dimer by yeast DNA polymerase $\eta$ ", Proc. Natl. Acad. Sci. USA, vol. 100, pp. 12093-12098, 2003.

[93] G.S. Kozmin, Y.I. Pavlov, T.A. Kunkel, E. Sage. "Roles of Saccharomyces cerevisiae DNA polymerases Pol\{eta\} and Pol $\{$ zeta $\}$ in response to irradiation by simulated sunlight", Nucleic Acids Res., vol. 31, pp. 4541-4552, 2003.

[94] P.E.M. Gibbs, J. McDonald, R. Woodgate and C.W. Lawrence, "The relative roles in vivo of Saccharomyces cerevisiae Pol $\eta$, Pol $\zeta$, Rev1 protein and Pol32 in the bypass and mutation induction of an abasic site, T-T (6-4) photoadduct and T-T cissyn cyclobutane dimer", Genetics, vol. 169, pp. 575-582, 2005.

[95] Y. Wang, R. Woodgate, T.P. McManus, S. Mead, J.J. McCormick and V.M. Maher, "Evidence that in xeroderma pigmentosum variant cells, which lack DNA polymerase $\eta$, DNA polymerase 1 causes the very high frequency and unique spectrum of UV-induced mutations", Cancer Research, vol. 67, pp. 3018-3026, 2007.

[96] S. Shachar, O. Ziv, S. Avkin, S. Adar, J. Wittschieben, T. Reißner, S. Chaney, E.S. Friedberg, Z. Wang, T. Carell, N. Geacintov and Z. Livneh, "Two-polymerase mechanisms dictate error-free and error-prone translesion DNA synthesis in mammals", EMBO J., vol. 28, pp. 383-393, 2009.

[97] R. Kasiviswanathan, M.A. Gustafson, W.C. Copeland and J.N. Meyer, "Human mitochondrial DNA polymerase $\gamma$ exhibits potential for bypass and mutagenesis at UV-induced cyclobutane thymine dimers", J. Biol. Chem., vol. 287, pp. 9222-9229, 2012.

[98] G. Raghunathan, T. Kieber-Emmons, R. Rein and I.L. Alderfer, "Conformation features of DNA containing a cis-syn photodimer", J. Biomol. Struct. Dyn., vol. 7, pp. 899-913, 1990.

[99] M.G. Cooney and J.H. Miller, "Calculated distortions of duplex DNA by a cis, syn cyclobutane thymine dimer are unaffected by a 3' TpA step", Nucleic Acids Res., vol. 25, pp. 1432-1436, 1997.

[100] K. McAteer, Y. Jing, J. Kao, J.-S. Taylor and M.A. Kennedy. "Solution-state structure of a DNA dodecamer duplex containing a Cis-syn thymine cyclobutane dimer, the major UV photoproduct of DNA", J. Mol. Biol., vol. 282, pp. 10131032 .

[101] H. Yamaguchi, D.M. van Aalten, M. Pinak, A. Furukawa, R. Osman, "Essential dynamics of DNA containing a cis.syn cyclobutane thymine dimer lesion", Nucleic Acids Res., vol. 26, pp. 1939-1946, 1998. 